\title{
A efetividade dos direitos sociais constitucionais e a liberdade sindical
}

\section{Gilberto Stürmer ${ }^{1}$}

\begin{abstract}
Sumário: Introdução; 1. Conflitos coletivos de trabalho; 2. Formas de solução dos conflitos coletivos de trabalho; 3 . Autocomposição - negociação coletiva; 4.Convenção coletiva de trabalho; 5. Liberdade sindical; Conclusões; Referências.
\end{abstract}

\begin{abstract}
Resumo: O artigo apresenta uma análise do sistema de relações coletivas de trabalho vigente no Brasil, no que diz respeito aos conflitos coletivos de trabalho e suas formas de solução, cotejando-o com o conceito de liberdade sindical protagonizado pela Organização Internacional do Trabalho. Identifica, a partir dos aspectos sociológicos e jurídicos dos conflitos coletivos de trabalho, a sua forma de solução autocompositiva, com o procedimento de negociação coletiva de trabalho visando a uma Convenção Coletiva de Trabalho ou um Acordo Coletivo de Trabalho. Considerando que a negociação coletiva de trabalho tem preferência em um sistema de liberdade sindical, o artigo não trata das formas heterocompositivas (arbitragem e jurisdição) e autodefensivas (greve e lockout) de solução dos conflitos. Por fim, conclui inexistir liberdade sindical no Brasil e propõe uma solução jurídica para esta adoção.
\end{abstract}

Palavras-chave: liberdade sindical; negociação coletiva de trabalho.
Abstract: The article presents an analysis of the current system of collective relations of work in Brazil, concerning the collective conflicts of work and their means of solution, by comparing it with the concept of union freedom, which was led by the International Labor Organization. According to the legal and sociological aspects of collective conflicts of work, it identifies a self-compositional way of solution that aims for a Collective Labor Convention or a Collective Agreement of Labor through the collective bargaining of labor procedure. Therefore, considering that the collective bargaining of labor has priority in a system of union freedom, the article does not deal with heterocompositional (arbitration and jurisdiction) and self-defensive (strike and lockout) means of conflicts' solution. Otherwise, it states the inexistence of union freedom in Brazil and proposes a legal solution for such adoption.

Keywords: union freedom; collective bargaining of labor.

\footnotetext{
1 Advogado, professor de Direito do Trabalho na Faculdade de Direito da PUCRS, mestre em Direito pela PUCRS, doutor em Direito do Trabalho pela UFSC.
} 


\section{Introdução}

O Título VI da Consolidação das Leis do Trabalho trata das convenções e acordos coletivos de trabalho. Dispõem sobre a matéria os artigos 611 a 625 do diploma consolidado.

A Constituição Federal reconhece as convenções e acordos coletivos de trabalho, nos artigos 7o, inciso XXVI e 8o, inciso VI.

No Título $\mathrm{X}$ da Consolidação, estão dispostas as regras sobre o processo judiciário do trabalho e, no capítulo IV do referido título, a lei dispõe sobre os dissídios coletivos. A seção III, que abriga os artigos 868 a 871, trata da extensão das decisões, ou seja, da possibilidade que o Tribunal do Trabalho tem de estender normas coletivas vigentes em uma parte da categoria para outra, ou, ainda, de estender normas coletivas de uma mesma categoria, de uma base territorial para outra, na mesma jurisdição.

Outra fonte formal de direito a tratar dos dissídios coletivos era a Instrução Normativa do Tribunal Superior do Trabalho no 4, de 8 de junho de 1993 que, embora revogada, continua a dar substrato ao procedimento. Da mesma forma, a Lei no 8.984 , de 8 de fevereiro de 1995, que dispõe sobre a "competência da Justiça do Trabalho para conciliar e julgar os dissídios que tenham origem no cumprimento de convenções coletivas de trabalho ou acordos coletivos de trabalho, mesmo quando ocorram entre sindicatos ou entre sindicato de trabalhadores e empregador." Não há previsão legal expressa no sentido de extensão de convenções ou acordos coletivos pelos Tribunais do Trabalho.

Por outro lado, a Emenda Constitucional no 45, de dezembro de 2004, alterando a redação do parágrafo $2^{\circ}$ do artigo 114 da Constituição Federal, mitigou mas não extinguiu o Poder Normativo da Justiça do Trabalho. Dispõe a nova redação do referido dispositivo:

Art.114

$\S 22^{\circ}$. Recusando-se qualquer das partes à negociação coletiva ou à arbitragem, é facultado às mesmas, de comum acordo, ajuizar dissídio coletivo de natureza econômica, podendo a Justiça do Trabalho decidir o conflito, respeitadas as disposições mínimas legais de proteção ao trabalho, bem como as convencionadas anteriormente. 
Ora, se a Justiça do Trabalho decide conflito coletivo de natureza econômica, por certo está exercendo o Poder Normativo, ainda que mitigado pelo ajuizamento de "comum acordo". Não se discute aqui a expressão. O fato é que os Tribunais do Trabalho estão convictos da obrigatoriedade ou não do ajuizamento conjunto. ${ }^{2}$

\section{Conflitos coletivos de trabalho}

Os conflitos de trabalho têm um divisor de águas. É da natureza humana que, aqueles que dão a sua força de trabalho para outrem, busquem sempre melhores condições de trabalho e de salário.

Por outro lado, os que dispõem da atividade econômica visam ao lucro. Não há, em um caso e em outro, juízo de valor. Trata-se apenas de realidade oriunda da própria natureza humana. Na medida em que o trabalhador subordinado busca melhores condições de trabalho, e o empregador, dono do empreendimento busca lucro, há um natural conflito de trabalho de ordem sociológica. Tal conflito é solucionado pelo contrato. ${ }^{3}$

Este é o divisor de águas, já que os conflitos posteriores ao contrato têm natureza jurídica, ou seja, em via de regra, em geral discutem-se cláusulas desrespeitadas ou cuja interpretação é divergente.

Inserem-se nesse contexto, os conflitos de natureza econômica, já que, estabelecidos os parâmetros iniciais, a tendência é buscar sempre o melhor. Para Sergio Pinto Martins

[...] os conflitos coletivos do trabalho podem ser econômicos ou de
interesse e jurídicos ou de direito.
Os conflitos econômicos são aqueles nos quais os trabalhadores
reivindicam novas condições de trabalho ou melhores salários. Já nos
conflitos jurídicos tem-se por objeto apenas a declaração da existência
ou inexistência de relação jurídica controvertida, como ocorre em dis-
sídio coletivo em que se declara a legalidade ou ilegalidade da greve. ${ }^{4}$

2 O Tribunal Superior do Trabalho firmou precedente sobre condição para dissídio coletivo, ao decidir no DC 165049/2005-000-00-00.4, que a expressão "comum acordo" quer dizer petição conjunta e, portanto, seria uma condição sui generis da ação.

3 No caso da relação individual, o contrato de trabalho; no caso das relações coletivas, as normas coletivas (acordo, convenção, sentença normativa ou laudo arbitral).

4 MARTINS, Sergio Pinto. Direito do Trabalho. 15. ed. São Paulo: Atlas, 2002, p. 709. 
[...] conflito não é apenas um fenômeno de dimensões sociológicas. É também um fato jurídico, estruturado em conjunto com instrumentos criados pela cultura jurídica dos povos, incluído nos sistemas de organização normativa da sociedade, indispensáveis para o equilíbrio da vida na sociedade e nas relações entre as pessoas e os grupos. ${ }^{5}$

Com efeito, sendo o conflito de trabalho e, especialmente, o conflito coletivo de trabalho, um fato social e jurídico, é certo que exista por insatisfação, mas também é certo que exista com o objetivo fundamental de busca da paz social, o que se dá através dos instrumentos de solução previstos no ordenamento jurídico.

\section{Formas de solução dos conflitos coletivos de trabalho}

As formas de solução ou de composição dos conflitos coletivos de trabalho são basicamente três, com suas subdivisões. Martins fala em autodefesa, autocomposição e heterocomposição. ${ }^{6}$

Para melhor observância da técnica, inicia-se pela autocomposição, que é a forma de solução dos conflitos trabalhistas realizada pelas próprias partes. ${ }^{7}$ As fontes formais de Direito do Trabalho privilegiam a autocomposição. ${ }^{8}$ É meio autocompositivo de solução dos conflitos coletivos de trabalho, a negociação coletiva. O resultado da negociação pode ser a convenção coletiva de trabalho ${ }^{9}$ ou o acordo coletivo de trabalho. ${ }^{10}$

A heterocomposição dos conflitos coletivos de trabalho surge ante o insucesso da negociação e pressupõe a participação de uma fonte suprapartes, com a prerrogativa de imposição da solução do conflito, à qual as partes deverão se submeter.

5 NASCIMENTO, Amauri Mascaro. Compêndio de Direito Sindical. 2. ed. São Paulo: LTr, 2000, p. 253.

6 NASCIMENTO, 2000, p. 710.

7 Ibidem.

8 É o caso da Constituição Federal, nos artigos 7oㅡ, XXVI; 8o, III e VI; 114, § 2o; e da Consolidação das Leis do Trabalho, nos artigos 611, 611, § 1ํㅡ, e 616.

9 Art. 611, da CLT.

10 Art. 611, § 1으, da CLT. 
São formas tradicionais de heterocomposição, a $\operatorname{arbitragem~}^{11}$ e a jurisdição. ${ }^{12}$

Cabe aqui registrar uma posição contrária à grande maioria da doutrina, que entende a mediação como forma heterocompositiva de solução dos conflitos coletivos de trabalho. ${ }^{13}$

É entendimento deste autor, que a mediação seria uma forma híbrida entre autocomposição e heterocomposição dos conflitos. Ocorre que há a participação de um terceiro (em regra a autoridade regional do Ministério do Trabalho), mas não há imposição obrigatória da solução apresentada pelo mediador, como ocorre na arbitragem e na jurisdição.

Por fim, a autodefesa, como forma em que as próprias partes procedem à defesa dos seus interesses. ${ }^{14}$ É dividida em greve ${ }^{15} \mathrm{e}$ lockout. ${ }^{16}$

\section{Autocomposição - negociação coletiva}

As formas de solução dos conflitos coletivos de trabalho são levadas a efeito por meios legais que buscam o chamado fim normativo. ${ }^{17}$ $\mathrm{Na}$ autocomposição, o meio utilizado é a negociação coletiva. Para Amauri Mascaro Nascimento, a negociação coletiva é característica do plurinormativismo do Direito, já que o seu resultado (convenção coletiva de trabalho) tem força de lei entre as partes. ${ }^{18}$

Segundo a Convenção n⿳o 154 da Organização Internacional do Trabalho, a Negociação Coletiva compreende todas as negociações que

\footnotetext{
11 Art. 114, § 2º da Constituição Federal e Lei no 9.307/96.

12 Art. 114, § 2º da Constituição Federal, arts. 856 a 875, da CLT, IN/TST 04/1993.

13 MARTINS, 2002, p. 710.

14 MARTINS, 2002, p. 710.

15 Na forma do art. 2º, da Lei no 7.783/89, “greve é a suspensão coletiva, temporária e pacífica total ou parcial, de prestação pessoal de serviços a empregador".

16 "Paralisação das atividades, por iniciativa do empregador, com o objetivo de frustrar negociação ou dificultar o atendimento de reivindicações dos respectivos empregados" (art. 17 da Lei no 7.783/89). O lockout é proibido no Brasil.

17 As normas coletivas (acordos coletivos de trabalho, convenções coletivas de trabalho, sentenças normativas e laudos arbitrais) são leis entre as partes.

18 MARTINS, 2002, p. 267.
} 
tenham lugar entre, de uma parte o empregador, um grupo de empregadores ou uma organização ou várias organizações de empregadores e, de outra parte, uma ou várias organizações de trabalhadores, visando a: 1) fixar as condições de trabalho e de emprego; 2) regular as relações entre empregadores e trabalhadores; 3 ) regular as relações entre empregadores ou suas organizações e uma ou várias organizações de trabalhadores ou alcançar todos estes objetivos de uma só vez.

É, pois, uma forma de ajuste de interesses entre as partes, que acertam as diferentes posições existentes, visando a encontrar uma solução capaz de compor suas posições. ${ }^{19}$

No Brasil, o procedimento da negociação coletiva segue os seguintes passos:

1) Os sindicatos trabalhistas comunicam aos sindicatos patronais ou diretamente às empresas as suas reivindicações, iniciandose um procedimento de negociação direta, sem interferência do Estado. A lei obriga as partes a manter o diálogo (art. 616), e o Poder Judiciário tem admitido a instauração de instância (ajuizamento de dissídio coletivo) somente com prova robusta de que houve negociação e que essa negociação se esgotou.

2) Havendo recusa à negociação, a DRT poderá convocar mesaredonda, iniciando-se, assim, a mediação do delegado regional do Trabalho que, como em toda mediação, não terá poderes decisórios, mas apenas apresentará propostas que as partes aceitarão ou não.

3) Havendo iminência de greve, também poderá ser convocada mesa-redonda pela Superintendência Regional do Trabalho e do Emprego (antiga DRT).

4) Não havendo autocomposição (convenção ou acordo coletivo de trabalho), sem ou com mediação, a lei autoriza a greve, segundo procedimento e nas hipóteses previstas.

5) Finalmente, não havendo autocomposição, o conflito buscará a solução através da heterocomposição, transferindo-se para os tribunais do trabalho, caso as partes não tenham preferido a arbitragem (art. 114 e parágrafos da Constituição Federal).

19 MARTINS, 2002, p. 727. 
Ajuizado o dissídio coletivo, este será julgado pelos Tribunais do Trabalho (TRTs e TST) que, através de uma sentença normativa, decidirão o conflito, respeitadas, na decisão, as disposições mínimas legais de proteção ao trabalho, bem como as convencionadas anteriormente.

O poder judiciário age como poder legislativo, eis que fixa normas a serem observadas pelas partes conflituadas.

Consoante previsão constitucional, a negociação coletiva é requisito para a arbitragem e para a jurisdição. ${ }^{20}$ Ademais, a própria CLT, ${ }^{21}$ condiciona a instauração da instância à comprovação cabal e inequívoca da tentativa de negociação prévia. A negociação coletiva distingue-se da convenção e do acordo coletivo de trabalho, já que se trata de procedimento que visa a superar divergência entre as partes, e o seu resultado é a convenção ou o acordo coletivo de trabalho. ${ }^{22}$

\section{Convenção coletiva de trabalho}

A Constituição Federal reconhece as convenções e os acordos coletivos de trabalho. ${ }^{23}$ e determina, que "ao sindicato cabe a defesa dos direitos e interesses coletivos ou individuais da categoria, inclusive em questões judiciais ou administrativas", ${ }^{24}$ e, ainda, que "é obrigatória a participação dos sindicatos nas negociações coletivas de trabalho", ${ }^{25}$

Como resultado das negociações coletivas de trabalho (formas autocompositivas de solução dos conflitos coletivos de trabalho), o ordenamento jurídico abriga as convenções e os acordos coletivos de trabalho.

Segundo o artigo 611, da Consolidação das Leis do Trabalho, “convenção coletiva de trabalho é o acordo de caráter normativo pelo

\footnotetext{
20 Art. 114, § 2‥

21 Art. 856 e segs.

22 Ver MARTINS, 2002, p. 727.

23 Art. 7ํ. São direitos dos trabalhadores urbanos e rurais, além de outros que visem à melhoria de sua condição social: XXVI - reconhecimento das convenções e acordos coletivos de trabalho.

24 Art. 8으. III.

25 Art. 8, VI.
}

Revista Seqüência, no 58, p. 9-22, jul. 2009. 
qual dois ou mais sindicatos representativos de categorias econômicas e profissionais estipulam condições de trabalho aplicáveis, no âmbito das respectivas representações, às relações individuais de trabalho."

Com efeito, pelo menos dois sindicatos - de um lado o dos trabalhadores, e de outro o dos empregadores - colocam um fim no conflito através de um acordo (negociação) que estabelece regras aplicáveis às relações individuais de trabalho da respectiva categoria no âmbito de sua representação, obedecida a regra da unicidade sindical.

O caráter é normativo porque a convenção coletiva é lei entre as partes. Por se tratar de um contrato, há também o caráter obrigacional das cláusulas e condições que estipulam regras entre os sindicatos convenentes. O parágrafo primeiro, do artigo 611 da CLT, dispõe que:

[...] é facultado aos sindicatos representativos de categorias profissionais celebrar Acordos Coletivos com uma ou mais empresas da correspondente categoria econômica, que estipulem condições de trabalho, aplicáveis no âmbito da empresa ou das empresas acordantes às respectivas relações de trabalho.

Assim, em menor escala, o sindicato dos trabalhadores poderá negociar com uma ou mais empresas, para estipular regras aplicáveis às relações de trabalho naquelas empresas.

Apesar de posições em contrário, entende-se que o dispositivo foi recepcionado pela Constituição Federal de 1988, já que o artigo 7o, inciso XXVI, da Lei Maior reconhece as convenções e acordos coletivos de trabalho. Assim, quando o artigo $8^{\circ}$, inciso VI, determina ser obrigatória a participação dos sindicatos nas negociações coletivas de trabalho, é certo estar se referindo ao sindicato dos trabalhadores (categoria profissional).

$\mathrm{O}$ artigo 616, da CLT, determina que "os sindicatos representativos de categorias econômicas ou profissionais e as empresas, inclusive as que não tenham representação sindical, quando provocados, não podem recusar-se à negociação coletiva, que visa à convenção ou ao acordo coletivo de trabalho.

Registre-se, ainda, que, nos termos do artigo 620 da CLT, as condições estabelecidas em convenção, quando mais favoráveis, 
prevalecerão sobre as estipuladas em acordo. Isto porque, sendo especial, o acordo, em regra, prevalece sobre a convenção. Todavia, em face do princípio protetor, no Direito do Trabalho vige a regra da norma mais favorável ao trabalhador, o que explica a regra prevista no artigo 620 da CLT. ${ }^{26}$

\section{Liberdade sindical}

O sistema sindical brasileiro nasceu, cresceu e floresceu sob os nefastos mantos do corporativismo e do intervencionismo. Embora signatário da Organização Internacional do Trabalho (OIT) desde a sua criação em 1919, o Brasil não recepcionou a principal Convenção da entidade, qual seja, a no 87, publicada em 1948 e que dispõe sobre liberdade sindical. Foi somente com a promulgação da atual Constituição Federal, em 5 de outubro de 1988, que alguma luz de liberdade sindical surgiu no horizonte.

$\mathrm{O}$ artigo $8^{\circ}$ da Carta dispõe que é livre a associação profissional ou sindical e determina que a lei não poderá exigir autorização do Estado para a fundação do sindicato, ressalvado o registro no órgão competente, vedadas ao Poder Público a interferência e a intervenção na organização sindical. ${ }^{27}$ Ocorre que o sindicalismo nacional ainda sofre com o intervencionismo e com a ausência de liberdade plena. Os traços marcantes são os seguintes:

Unicidade sindical: segundo o artigo 8o, II, da Constituição Federal, [...] é vedada a criação de mas de uma organização sindical, em qualquer grau, representativa de categoria profissional ou econômica, na mesma base territorial, que será definida pelos trabalhadores ou empregadores interessados, não podendo ser inferior à área de um município. A alternativa, através de emenda constitucional, seria o pluralismo ou até a unidade sindical, em que os sindicatos se unem sem imposição estatal.

Enquadramento sindical por categoria: segundo o artigo 570 e seguintes da CLT, o enquadramento sindical no Brasil se dá por categoria

\footnotetext{
${ }^{26}$ Ver RODRIGUEZ, Américo Plá. Princípios de Direito do Trabalho. Trad. Wagner D. Giglio. 1. ed. São Paulo: LTr, 1996, p. 53.

27 Art. 8oㅡ, caput e inciso I.
} 
idêntica, similar ou conexa, ${ }^{28}$ o que quer dizer que um trabalhador, ou um empregador, que exerça determinada atividade (por exemplo, ramo metalúrgico), não pode ser representado por outro sindicato que, por ventura, lhe seja mais representativo. ${ }^{29}$ Alteração legislativa, em conjunto com as modificações constitucionais acima citadas, resolveria a questão.

Contribuição sindical compulsória: prevista nos artigos 578 e seguintes da CLT, existe desde 1940 e fere de morte o princípio da liberdade sindical e também a regra constitucional que diz que ninguém será obrigado a filiar-se ou a manter-se filiado a sindicato. ${ }^{30} \mathrm{Os}$ trabalhadores, os autônomos, os profissionais liberais e os empregadores são obrigados a contribuir para o sistema sindical. ${ }^{31}$ Tal circunstância, além de ser contrária à liberdade, faz com que se mantenham sindicatos que não são representativos, quando não, verdadeiros fantasmas. A modificação depende de alteração na lei: mais do que isso, depende da superação do lobismo, do conservadorismo, do corporativismo e do intervencionismo que emperram o sindicalismo no Brasil.

Efetivo exercício do direito de greve: a Constituição Federal prevê o direito nos artigos 9ำ (trabalhadores privados) e 37, VII (servidores públicos). Os servidores públicos ainda não têm legislação que regulamente o direito. Os trabalhadores privados têm o seu direito de greve regulado pela Lei no 7.783, de 28 de junho de 1989, mas a liberdade ao exercício do direito ainda é muito reprimida. O que não se pode olvidar é que, mais do que um fato jurídico, a greve é um fato social.

Estes são alguns exemplos da ausência de liberdade sindical no Brasil. A PEC n 369/2005, o Anteprojeto de lei de Reforma Sindical (sobrestado) e os demais textos legislativos propostos, não têm o condão

28 Nos termos do parágrafo único, do artigo 570 da CLT, “quando os exercentes de quaisquer atividades ou profissões se constituírem, seja pelo número reduzido, seja pela natureza mesma dessas atividades ou profissões, seja pelas afinidades existentes entre elas, em condições tais que não se possam sindicalizar eficientemente pelo critério de especificidade de categoria, é-lhes permitido sindicalizar-se pelo critério de categorias similares ou conexas, entendendo-se como tais as que se acham compreendidas nos limites de cada grupo constante do quadro de atividades ou profissões."

29 Por tal circunstância entende-se que, salvo exceções, o Capítulo II, do Título V da CLT, que trata do enquadramento sindical e abrange os artigos 570 a 577, foi recepcionado pela Constituição Federal de 1988.

30 Art. 8o, V, da Constituição Federal.

31 Art. 580 e incisos, da CLT. 
de afastar do sindicalismo nacional a ausência da liberdade sindical, já que não atacam, de forma efetiva, os problemas aqui referidos. ${ }^{32}$

Entende-se que a Emenda Constitucional no 45/2004 deu uma oportunidade jurídica ímpar para o advento da liberdade sindical no Brasil. O novo parágrafo $3^{\circ}$, do artigo $5^{\circ}$, dispõe que os tratados e convenções internacionais sobre direitos humanos que forem aprovados em cada casa do Congresso Nacional, em dois turnos, por três quintos dos votos dos respectivos membros, serão equivalentes às emendas constitucionais. ${ }^{33}$

É indiscutível que a Convenção 87 da OIT, que trata de liberdade sindical é, de fato, um tratado sobre direitos humanos. Havendo vontade política para superar a questão formal, o status de emenda constitucional abriria as portas para o pluralismo sindical, o fim do enquadramento, da contribuição compulsória e do poder normativo.

Para finalizar, este autor propõe um conceito de liberdade sindical, em que efetivamente não haja lugar para a unicidade sindical, o enquadramento sindical, a contribuição compulsória e o poder normativo da Justiça do Trabalho. ${ }^{34}$

[...] direito de trabalhadores, entendidos como tal empregados, empregadores, autônomos e profissionais liberais, de livremente constituírem e desconstituírem sindicatos; de individualmente ingressarem e saírem dos sindicatos conforme seus interesses e sem limites decorrentes da profissão à qual pertençam; de livremente administrarem as organizações sindicais, constituírem órgãos superiores e de associarem-se a órgãos internacionais; de livremente negociarem sem qualquer interferência do Poder Público (executivo, legislativo ou judiciário); e de livremente exercerem o direito de greve, observadas as formalidades legais; tudo isso sem limitação de base territorial e num regime de pluralismo, sendo o sistema financiado única e exclusivamente pelas contribuições espontâneas por eles mesmos fixadas.

32 No momento em que é produzido este artigo, o texto encontra-se parado no Congresso Nacional, devendo ser retomadas as discussões na nova legislatura.

33 Ver STÜRMER, Gilberto. A Liberdade Sindical na Constituição da República Federativa do Brasil de 1988 e sua relação com a Convenção no 87 da Organização Internacional do Trabalho. Porto Alegre: Livraria do Advogado, 2007, p. 64-65.

34 Ibidem, p. 60-61. 
Não há dúvida, portanto, de que a constante busca pela efetivação dos direitos sociais previstos na Constituição Federal de 1988, mais especificamente nos seus artigos $7^{\circ}$ e $8^{\circ}$, passa no Brasil necessária e obrigatoriamente pela implantação da liberdade sindical.

\section{Conclusão}

Os conflitos coletivos de trabalho têm origem sociológica antes de jurídica.

O sistema legal brasileiro privilegia a negociação coletiva de trabalho como meio de solução dos conflitos e as convenções e acordos coletivos de trabalho como resultado da autocomposição.

Tal privilégio está expresso na Constituição Federal, artigos 7oㅡㄴ,

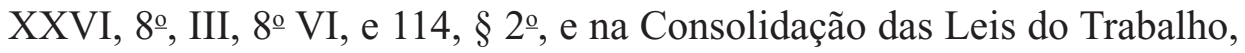
nos artigos $611,611, \S 1$ 은 616 e parágrafos.

As formas heterocompositivas (arbitragem e jurisdição) e autodefensivas (greve e lockout) de solução dos conflitos de trabalho são utilizadas somente ante o insucesso da negociação. Entende-se, ainda, que a mediação é uma forma híbrida de solução dos conflitos de trabalho, já que a fonte suprapartes não impõe a sua decisão, mas apenas busca solucionar o conflito.

Para melhor aproveitamento da negociação coletiva no sistema brasileiro, deve ser implantada a liberdade sindical plena, recepcionando a Convenção 87 da OIT, e estabelecendo o pluralismo sindical, o enquadramento sindical livre, o fim da contribuição sindical compulsória, a abertura ao direito constitucional de greve e a efetiva extinção do poder normativo da Justiça do Trabalho.

A adoção da Convenção 87 da OIT, que é um tratado internacional de direitos humanos, deveria se dar através do instrumento previsto no artigo 5, parágrafo 3o, da Constituição Federal, com redação dada pela Emenda no 45/2004. Nesse contexto, certamente seria aberto um caminho de implantação efetiva dos direitos sociais preconizados pela Carta. 


\section{Referências}

AVILÉS, A. O. Compendio de derecho sindical. Madrid: Editorial Tecnos, 1998.

BATALHA, W. S. C; BATALHA, S. M. L. Sindicatos - Sindicalismo. São Paulo: LTr, 1994.

CHIARELLI, C. A. O trabalho e o sindicato - evolução e desafios. São Paulo: LTr, 2005.

GUERRERO, E. Manual de derecho del trabajo. México: Porrúa, 13. ed., 1983.

LAIMER, A. G. O Novo Papel dos Sindicatos. São Paulo: LTr, 2003.

LEBRE, E. A. T. Direito coletivo do trabalho. Porto Alegre: Síntese, 1999.

MAGANO, O. B. Manual de direito do trabalho - Volume III. São Paulo: LTr, 1984.

MANGLANO, C. M. Derecho sindical. Madrid: Editorial Dykinson, 1996.

MARTINS, S. P. Contribuição confederativa. São Paulo: LTr, 1996.

MARTINS, S. P. Contribuições sindicais. 4. ed. São Paulo: Atlas, 2004.

MARTINS, S. P. Direito do trabalho. 19. ed. São Paulo: Atlas, 2004.

MARTINS, S. P. Flexibilização das condições de trabalho. São Paulo: Atlas, 2000.

MORAES FILHO, Evaristo; MORAES, Antonio Carlos Flores de. Introdução ao direito do trabalho. 8. ed. São Paulo: LTr, 2000.

MORAES FILHO, Evaristo; MORAES, Antonio Carlos Flores de. $O$ problema do sindicato único no Brasil. São Paulo: Alfa-Omega, 1978.

NASCIMENTO, Amauri Mascaro. Compêndio de direito sindical. 2. ed. São Paulo: LTr, 2000.

OLEA, Manuel Alonso. Introducción al derecho del trabajo. 5. ed. Madrid: Civitas, 1994. 
OLIVEIRA, Olga Maria Boschi Aguiar de. A Universalidade do Princípio da Liberdade Sindical. Revista da Faculdade de Direito da UFSC. Porto Alegre: Síntese, v. 1, p. 139-156, 1998.

OLIVEIRA, O. M. B. A; STÜRMER, G. As concepções do direito de Ronald Dworkin e a liberdade sindical no Brasil. Revista LTr. São Paulo: LTr, v. 11/04, p. 1338-1342, 2004.

RODRIGUEZ, A. P. Princípios de direito do trabalho. São Paulo: LTr, 1996.

ROMITA, A. S. Direito do trabalho - temas em aberto. São Paulo: LTr, 1998.

RUSSOMANO, M. V. Princípios gerais de direito sindical. 2. ed. Rio de Janeiro: Forense, 1998.

SARLET, I. W. A eficácia dos direitos fundamentais. Porto Alegre:

Livraria do Advogado Editora, 1998.

STÜRMER, G. A liberdade sindical na Constituição da República Federativa do Brasil de 1988 e sua relação com a Convenção 87 da Organização Internacional do Trabalho. Porto Alegre: Livraria do Advogado Editora, 2007.

VIANNA. L. W. Liberalismo e sindicato no Brasil. 3. ed. Rio de Janeiro: Paz e Terra, 1978. 